\title{
Desempenho reprodutivo e metabólitos sanguíneos de ovelhas lle de France sob suplementação com sal orgânico ou sal comum durante a estação de monta
}

\section{Luiz Antero de Oliveira Peixoto ${ }^{1^{*}}$, Maria Teresa Moreira Osório ${ }^{2}$, José Carlos da Silveira Osório $^{2}$, José Laerte Nörnberg ${ }^{3}$, Marceli Pazini ${ }^{4}$}

\footnotetext{
${ }^{1}$ Doutorando em Zootecnia-UFPel.

2 Departamento de Zootecnia - UFPel.

${ }^{3}$ Departamento de Tecnologia e Ciência dos Alimentos - UFSM.

${ }^{4}$ Graduanda em Medicina Veterinária - UFSM.
}

RESUMO - Avaliou-se o desempenho reprodutivo de ovelhas sob suplementação com sal orgânico ou sal comum durante a estação de monta e sua associação com os constituintes metabólicos do sangue. O experimento foi conduzido no período de novembro de 2005 a maio de 2006 utilizando-se 40 ovelhas da raça Ile de France. Durante a estação de monta, as ovelhas permaneceram em duas áreas de campo nativo, cada uma com 15 hectares, e foram distribuídas em dois grupos, conforme o tipo de suplementação: recebendo apenas mistura mineral (sal+fosfato) ou suplementação diária de sal orgânico. Foram analisados os indicadores bioquímicos do perfil nutricional por meio da quantificação de albumina, ureia, glicose, colesterol e triglicerídeos do soro sanguíneo. As ovelhas sob suplementação com mineral orgânico tiveram teor de nitrogênio ureico sérico superior ao daquelas que receberam mineral na forma tradicional (39,00 vs 35,69 $\mathrm{mg} / \mathrm{dL}$, respectivamente). Os demais componentes bioquímicos avaliados não apresentaram diferença entre as formas de suplementação. Os níveis séricos de albumina, ureia, glicose e colesterol apresentaram variação entre os períodos avaliados durante a estação de monta. Os níveis séricos de albumina e nitrogênio ureico não influenciam a taxa de parição das ovelhas. A suplementação com mineral orgânico não melhora os índices reprodutivos do rebanho ovino na estação de monta das ovelhas.

Palavras-chave: mineral orgânico, ovinos, perfil metabólico, reprodução

\section{Reproductive performance and blood metabolites from lle de France ewes fed organic or common salt in the breeding season}

\begin{abstract}
The objective of this study was to evaluate the reproductive performance of ewes supplemented with organic or common mineral salt in the breeding season, and the effect on metabolic constituents of the blood. The experiment was carried out from November 2005 to May 2006 using 40 Ile de France breed ewes. During the breeding season, sheep grazed on two native pasture areas of 15 ha each and were distributed in two groups, depending on the supplementation: submitted to treatments: receiving only mineral mix (salt+phosphate) and receiving organic salt. Biochemical indicators of the nutritional status were analyzed by quantifying the serum albumin, urea, glucose, cholesterol and triglycerides of the blood serum. Ewes fed organic mineral had a higher rate of serum urea nitrogen than ewes that received salt in the traditional form (39.00 vs. $35.69 \mathrm{mg} / \mathrm{dL}$, respectively). The others biochemical components evaluated did not differ between treatments. The albumin, urea, glucose and cholesterol serum values differed between the evaluated periods during the breeding season. Serum albumin and urea nitrogen values did not influence the birth rate. Supplementation with organic salt do not improve the reproductive performance of ewes in the breeding season.
\end{abstract}

Key Words: metabolic profile, organic mineral, reproduction, sheep

\section{Introdução}

A ovinocultura no Rio Grande do Sul caracteriza-se pela criação extensiva, com os animais manejados exclusivamente em pastagem natural. Consequentemente, os índices reprodutivos do rebanho tornam-se baixos, com taxa de desmame de cordeiros muitas vezes menor que 70\% (Silva, 1992).

A adequada suplementação mineral na estação de monta é importante para um bom desempenho reprodutivo do rebanho. Os minerais necessários aos animais possuem funções essenciais, como na estrutura dos tecidos e 
biomoléculas, no metabolismo do animal, participando como cofatores enzimáticos e ativadores da ação hormonal, além de serem responsáveis pela pressão osmótica e pelo equilíbrio ácido-básico (González, 2000a).

A utilização de sais orgânicos (quelatados) na dieta de ruminantes visa aumentar a biodisponibilidade dos minerais no trato digestório. Segundo a AAFCO (1997), os minerais orgânicos são íons metálicos ligados quimicamente a uma molécula orgânica formando estruturas com características únicas de estabilidade e de alta absorção, conferindo alta biodisponibilidade mineral.

Recentemente, estudos têm utilizado como ferramenta para a avaliação do perfil metabólico em ruminantes a análise dos componentes bioquímicos do sangue, que refletem de maneira confiável o balanço entre o ingresso, o egresso e a metabolização dos nutrientes nos tecidos animais (González, 2000b). O perfil metabólico em animais de produção auxilia na avaliação de rebanhos com diferentes índices produtivos e reprodutivos.

Níveis séricos de ureia e albumina são os principais indicadores do metabolismo proteico em ruminantes. A ureia demonstra o estado proteico em curto prazo, enquanto a albumina o demonstra em longo prazo (Payne \& Paine, 1987). Conforme descrito por Wittwer et al. (1993) a ureia é sintetizada no fígado em quantidades proporcionais à concentração de amônia produzida no rúmen e sua concentração está diretamente relacionada aos níveis proteicos da ração e à relação energia:proteína da dieta. A albumina é considerada o indicador mais sensível para determinar o estado nutricional proteico, de modo que valores persistentemente baixos sugerem inadequado consumo protéico.

Por sua vez, a glicose é um metabólito que representa a via metabólica da energia, porém é pouco sensível às variações no aporte de energia da dieta, já que sua concentração sanguínea é regulada por um eficiente mecanismo hormonal destinado a manter constante as concentrações de glicose. Assim, o déficit de energia deve ser muito intenso para que diminua a concentração de glicose sanguínea (Rowlands, 1980).

Neste estudo objetivou-se avaliar o desempenho reprodutivo das ovelhas sob suplementação com sal orgânico ou comum durante a estação de monta e sua associação com os constituintes metabólicos do sangue.

\section{Material e Métodos}

As atividades de coleta de dados e amostras foram realizadas na Fazenda Tarumã, município de Júlio de
Castilhos, na região central do Rio Grande do Sul, no período de novembro de 2005 a maio de 2006.

Foram utilizadas 40 ovelhas sem cria ao pé da raça Ile de France, com peso médio inicial de $52 \mathrm{~kg}$, distribuídas de acordo com a idade e provenientes do mesmo rebanho. Antes da estação de monta, as ovelhas foram mantidas em mesma área de pastagem natural, momento em que iniciaram o período de adaptação à suplementação de 27 dias. A estação de monta ficou compreendida entre os dias $1^{\circ}$ de dezembro de 2005 e 11 de janeiro de 2006, totalizando 42 dias. A monta foi controlada e todos os dias ao final da tarde as ovelhas eram encaminhadas ao curral junto com o carneiro, que era marcado com tinta vermelha na porção ventral do tórax para identificação das ovelhas cobertas. A verificação das ovelhas cobertas era realizada diariamente no início da manhã, quando retornavam aos piquetes.

Durante a estação de monta, as ovelhas foram mantidas em duas áreas de campo nativo, cada uma de 15 hectares, e foram submetidas a dois regimes de suplementação: 20 ovelhas exclusivamente em regime de pastagem natural recebendo apenas mistura mineral (sal+fosfato); e 20 ovelhas mantidas em pastagem natural recebendo suplementação diária de sal orgânico (Tabela 1). Cada grupo de ovelhas era mantido durante uma semana em cada piquete para que $o$ piquete não interferisse nos resultados.

A suplementação mineral experimental das ovelhas foi realizada entre os dias 3 de novembro de 2005 (início da adaptação) e 11 de janeiro de 2006. A suplementação era realizada todos os dias no período da tarde em cochos de madeira cobertos em que somente as ovelhas do tratamento tinham acesso, no estilo creep feeding, ficando o acesso restrito aos animais reguladores. O suplemento foi fornecido à vontade.

As coletas de sangue das ovelhas para posterior avaliação dos constituintes metabólicos foram realizadas aos $0,14,28$ e 42 dias após o início do período de

Tabela 1 - Composição mineral dos suplementos

\begin{tabular}{lcc}
\hline Mineral & Sal orgânico & Mistura mineral (inorgânico) \\
\hline Cálcio & $120,00 \mathrm{~g}$ & $150 \mathrm{~g}$ \\
Fósforo & $87,00 \mathrm{~g}$ & $75 \mathrm{~g}$ \\
Sódio & $147,00 \mathrm{~g}$ & $124 \mathrm{~g}$ \\
Enxofre & $18,00 \mathrm{~g}$ & $12 \mathrm{~g}$ \\
Cobre & $590,00 \mathrm{mg}$ & $650 \mathrm{~g}$ \\
Cobalto & $40,00 \mathrm{mg}$ & $25,00 \mathrm{mg}$ \\
Cromo & $20,00 \mathrm{mg}$ & - \\
Ferro & $1.800,00 \mathrm{mg}$ & $2000,00 \mathrm{mg}$ \\
Iodo & $80,00 \mathrm{mg}$ & $40 \mathrm{mg}$ \\
Manganês & $1.300,00 \mathrm{mg}$ & $1000,00 \mathrm{mg}$ \\
Selênio & $15,00 \mathrm{mg}$ & $10,00 \mathrm{mg}$ \\
Zinco & $3.800,00 \mathrm{mg}$ & $2500,00 \mathrm{mg}$ \\
Molibdênio & $300,00 \mathrm{mg}$ & - \\
Flúor (máx.) & $870,00 \mathrm{mg}$ & - \\
\hline
\end{tabular}


suplementação mineral. As amostras de sangue foram coletadas da veia jugular em tubos de vácuo de $4 \mathrm{~mL}$ sem anticoagulante, devidamente identificados. A cada 12 amostras coletadas, era realizada a centrifugação a $2.500 \mathrm{rpm}$ por 15 minutos para obtenção do soro sanguíneo. O soro obtido foi armazenado em ependorfes de $2 \mathrm{~mL}$ e conservado a $-20^{\circ} \mathrm{C}$ até o momento da análise bioquímica. Foram analisados os indicadores bioquímicos do estado nutricional proteico pela quantificação de albumina e ureia sérica e os indicadores energéticos, pela determinação dos níveis séricos de glicose, colesterol e triglicerídeos.

Nos piquetes de pastagem natural em que as ovelhas permaneceram durante o período de suplementação mineral, foram estimadas a disponibilidade, a qualidade e a taxa de acúmulo diário de forragem de cada piquete.

Para avaliação da qualidade da forragem consumida pelos animais, no início de cada período experimental, antes de os animais entrarem no piquete, foram coletadas amostras de pasto utilizando-se a técnica de simulação do pastejo animal (Hand-plucked), com dois observadores treinados. Para determinação da disponibilidade de forragem, em $\mathrm{kg}$ de MS/ha, utilizou-se a técnica da "dupla amostragem", conforme técnica descrita por Wilm etal.(1944), além da taxa de acúmulo diário de matéria seca (TAD), realizada com a utilização de gaiolas de exclusão ao pastejo nos potreiros, com método semelhante ao descrito por Heringer \& Jacques (2002).

As amostras coletadas por simulação de pastejo e dupla amostragem foram analisadas no Núcleo Integrado de Desenvolvimento em Análises Laboratoriais (NIDAL) da Universidade Federal de Santa Maria (UFSM), para deteminação dos teores de matéria seca (MS), proteína bruta (PB) e fibra em detergente neutro (FDN).

O delineamento experimental utilizado foi inteiramente casualizado, em arranjo fatorial $2 \times 4$, com dois tratamentos e quatro períodos de coleta. Os resultados obtidos foram submetidos à análise de variância, seguida do teste $\mathrm{F}$, e as médias comparadas pelo teste Tukey a 5\% de significância utilizando-se o pacote estatístico SAS (1997).

O modelo matemático proposto para o experimento é o seguinte:

$$
\mathrm{Y}_{\mathrm{ij}}=\mu+\mathrm{T}_{\mathrm{i}}+\mathrm{PER}_{\mathrm{j}}+\varepsilon_{\mathrm{ij}}
$$

em que: $\mathrm{Y}_{\mathrm{ij}}=$ variáveis-dependentes; $\mu$ = média geral de todas as observações; $\mathrm{T}_{\mathrm{i}}=$ efeito do i-ésimo tratamento; $\operatorname{PER}_{\mathrm{j}}=$ efeito do período de ordem $\mathrm{j} ; \varepsilon_{\mathrm{ij}}=$ erro aleatório associado a cada observação.

Após a estação de monta, a variável período (PER) foi retirada do modelo.

A taxa de parição (cordeiros nascidos/ovelhas em cria) foi analisada pelo teste qui-quadrado.

\section{Resultados e Discussão}

A pastagem em que as ovelhas foram mantidas durante a estação de monta e gestação era composta de gramíneas e leguminosas nativas da região central do Rio Grande do Sul, com média da massa de forragem disponível de $861,85 \mathrm{~kg} \mathrm{MS} / \mathrm{ha}$ (Tabela 2).

Essa média foi regulada pelo método put and take para permanecer entre 800 e $1.000 \mathrm{~kg} \mathrm{MS} / \mathrm{ha}$, alimentação suficiente para que os animais pudessem manter peso e condição corporal necessários à sua demanda biológica.

Os teores de proteína bruta da pastagem não variaram durante esse período, com valores de $10,35 \%$ no residual e $16,02 \%$ na simulação de pastejo, médias suficientes para seu pleno desempenho reprodutivo.

Os teores de FDN foram bastante altos, representativos de uma pastagem natural do Rio Grande do Sul, com alta concentração de carboidratos estruturais, de mais lenta e difícil digestão. Essas condições adversas de pastagem natural foram planejadas visando maior contraste entre as duas fontes minerais utilizadas neste estudo.

Tabela 2 - Médias para massa de forragem disponível, teor de matéria seca (MS), taxa de acúmulo diário de MS, teores de proteína bruta e fibra em detergente neutro da pastagem no residual e na simulação de pastejo

\begin{tabular}{|c|c|c|c|c|c|}
\hline \multirow[t]{2}{*}{ Item } & \multicolumn{4}{|c|}{ Data } & \multirow[t]{2}{*}{ Média } \\
\hline & $2 / 11 / 2005$ & $6 / 12 / 2005$ & $4 / 1 / 2006$ & $31 / 1 / 2006$ & \\
\hline & \multicolumn{4}{|c|}{ Residual } & \\
\hline Massa de forragem, $\mathrm{kg} \mathrm{MS} / \mathrm{ha}$ & 585,55 & 828,36 & 762,50 & 1271,00 & 861,85 \\
\hline Matéria seca (MS), \% & 33,48 & 41,61 & 38,97 & 34,92 & 37,25 \\
\hline Taxa de acúmulo de MS, $\mathrm{kg} / \mathrm{ha} / \mathrm{dia}$ & & 19,12 & 2,87 & 21,60 & 14,53 \\
\hline Proteína bruta, \% & 12,41 & 9,84 & 9,54 & 9,61 & 10,35 \\
\hline \multirow[t]{2}{*}{ Fibra em detergente neutro, $\%$} & 63,49 & 75,38 & 77,38 & 77,94 & 73,55 \\
\hline & \multicolumn{4}{|c|}{ Simulação de pastejo } & \\
\hline Matéria seca, \% & & 38,84 & 46,62 & 48,39 & 44,62 \\
\hline Proteína bruta, \% & & 17,04 & 12,60 & 18,42 & 16,02 \\
\hline Fibra em detergente neutro, $\%$ & & 64,63 & 75,57 & 64,84 & 68,35 \\
\hline
\end{tabular}


$\mathrm{Na}$ avaliação da pastagem do dia $2 / 11 / 2005$, quando as ovelhas iniciaram seu período de adaptação à suplementação mineral, as características da forragem antes do período experimental apresentavam condições semelhantes às do período experimental, assim, não foi utilizada restrição alimentar antes da estação de monta, como forma de aumentar a taxa de gestação via flushing.

Segundo Contreras et al. (1990) o perfil metabólico em um rebanho ovino por categorias (borregas, gestantes, lactantes) tem potencial de indicar o status nutricional, quando se usam valores de referência e indicadores metabólicos apropriados. Neste trabalho o perfil metabólico de ovelhas Ile de France sem cordeiro ao pé (Tabela 3) durante a estação de monta manteve-se dentro dos intervalos de referência para esta espécie descrito por Contreras et al. (2000).

A albumina, pelo fato de necessitar de período mais longo para apresentar variações, não diferiu $(\mathrm{P}>0,05)$ entre as formas de suplementação mineral. Ribeiro et al. (2003) avaliaram o teor de albumina em cordeiras Corriedale mantidas em pastagem natural e também não verificaram diferença $(\mathrm{P}>0,05)$ ao longo do ano, mesmo com a variação na qualidade do pasto, e obtiveram valor médio de $3,26 \mathrm{mg} / \mathrm{dL}$.

Diferentemente do teor de albumina, nas ovelhas sob suplementação com mineral orgânico tiveram teor de nitrogênio ureio sérico (NUS) foi superior $(\mathrm{P}<0,05)$ ao observado nas ovelhas que receberam mineral na forma

Tabela 3 - Médias ajustadas e erros-padrão para os níveis séricos de albumina, nitrogênio ureico, glicose, colesterol e triglicerídeos

\begin{tabular}{lrrr}
\hline Item & \multicolumn{2}{c}{ Tipo de suplementação } & \multirow{2}{*}{$\mathrm{CV}, \%$} \\
\cline { 2 - 3 } & \multicolumn{1}{c}{ Sal comum } & \multicolumn{1}{c}{ Sal orgânico } & \\
\hline Albumina, $\mathrm{mg} / \mathrm{L}$ & $2,85 \pm 0,055$ & $2,79 \pm 0,056$ & 17,41 \\
Nitrogênio ureico, mg/dL & $35,68 \pm 0,79 \mathrm{~B}$ & $38,11 \pm 0,80 \mathrm{~A}$ & 18,89 \\
Glicose, $\mathrm{mg} / \mathrm{dL}$ & $61,83 \pm 2,04$ & $63,39 \pm 2,07$ & 25,13 \\
Colesterol, mg/dL & $78,00 \pm 2,72$ & $73,72 \pm 2,77$ & 27,77 \\
Triglicerídeo, mg/dL & $23,06 \pm 1,44$ & $23,04 \pm 1,47$ & 48,08 \\
\hline Médias seguidas de letras distintas na mesma linha diferem $(\mathrm{P}<0,05)$ pelo teste \\
Tukey.
\end{tabular}

tradicional (38,11 vs. 35,68 mg/dL, respectivamente). Como o teor de proteína bruta da pastagem foi de $16,02 \%$ (Tabela 2 ), acima do necessário para ovelhas desta categoria, o maior valor de NUS para a suplementação orgânica se deve ao fato de os minerais orgânicos atuarem como catalisadores dos processos de multiplicação celular dos microrganismos do rúmen, possibilitando melhorias no processo fermentativo ruminal, sendo importantes para a síntese de proteína microbiana (Ospina et al., 2000). Por isso produzem quantidade maior de amônia no rúmen, que é liberada na corrente sanguínea e convertida em ureia no fígado, podendo retornar ao trato gastrintestinal via saliva ou via transepitelial.

Os metabólitos sanguíneos que medem o estado nutricional energético não diferiram $(\mathrm{P}>0,05)$ entre as formas de suplementação mineral. A concentração de glicose sanguínea é relativamente constante no organismo animal, em razão de um eficiente mecanismo hormonal destinado à sua manutenção, e somente uma subnutrição muito severa seria capaz de levar os animais a um quadro hipoglicêmico. Os teores séricos de colesterol e triglicerídeos também não diferiram, em decorrência do adequado aporte nutricional e do bom escore corporal das ovelhas.

As taxas médias dos metabólitos sanguíneos diferiram $(\mathrm{P}<0,05)$ de acordo com o período de coleta durante a estação de monta, com exceção dos teores de triglicerídeos, que se mantiveram constantes (Tabela 4).

Brito et al. (2006), em pesquisa com ovelhas Lacaune e mestiças Lacaune $\times$ Texel na estação de monta, pré-parto e lactação, encontraram teor de triglicerídeo sérico superior ao deste trabalho na época de monta $(30,7 \mathrm{mg} / \mathrm{dL})$, possivelmente pela melhor qualidade da dieta, composta de silagem de milho, pasto verde e ração com $74 \%$ de NDT. Entretanto, assim como neste experimento, os teores de triglicerídeo não diferiram $(\mathrm{P}>0,05)$ na estação de monta $\mathrm{e}$ no decorrer da gestação, mesmo com as diferentes exigências dos animais neste período, o que confirma a hipótese de que os triglicerídeos séricos também não são sujeitos a grandes variações.

Tabela 4 - Médias ajustadas e erros-padrão para os níveis séricos de albumina, nitrogênio ureico (NUS), glicose, colesterol e triglicerídeos, de acordo com o período de coleta na estação de monta

\begin{tabular}{lccrr}
\hline Variável & \multicolumn{3}{c}{ Data de coleta } \\
\cline { 2 - 5 } & $1 / 12 / 2005$ & $14 / 12 / 2005$ & $28 / 12 / 2005$ & $11 / 1 / 2006$ \\
\hline Albumina, mg/L & $3,07 \pm 0,078 \mathrm{~A}$ & $3,06 \pm 0,078 \mathrm{~A}$ & $2,58 \pm 0,079 \mathrm{~B}$ & $2,58 \pm 0,079 \mathrm{~B}$ \\
Nitrogênio ureico, mg/dL & $44,29 \pm 1,11 \mathrm{~A}$ & $34,88 \pm 1,11 \mathrm{C}$ & $28,06 \pm 1,13 \mathrm{D}$ & $40,35 \pm 1,12 \mathrm{~B}$ \\
Glicose, $\mathrm{mg} / \mathrm{dL}$ & & $67,93 \pm 2,49 \mathrm{~A}$ & $58,50 \pm 2,53 \mathrm{~B}$ & $61,39 \pm 2,52 \mathrm{AB}$ \\
Colesterol, mg/dL & & $91,44 \pm 3,33 \mathrm{~A}$ & $65,34 \pm 3,37 \mathrm{~B}$ & $70,81 \pm 3,37 \mathrm{~B}$ \\
Triglicerídeo, mg/dL & & $23,24 \pm 1,76$ & $21,90 \pm 1,79$ & $24,01 \pm 1,78$ \\
\hline
\end{tabular}

Médias seguidas de letras distintas na mesma linha diferem $(\mathrm{P}<0,05)$ pelo teste Tukey. 
Os níveis séricos de albumina nas duas primeiras coletas $(3,07$ e $3,06 \mathrm{mg} / \mathrm{L})$ foram maiores $(\mathrm{P}<0,05)$ que nas duas últimas $(2,58 \mathrm{mg} / \mathrm{dL})$ (Tabela 4). Como nesse mesmo período não houve diferença entre os teores de proteína bruta da pastagem (Tabela 2), pode-se atribuir esta diferença à maior demanda proteica dessas ovelhas, já que a maioria foi fecundada na primeira metade do período de monta e suas exigências corresponderam ao período de gestação.

Os teores de nitrogênio ureico sérico, por representarem diretamente a quantidade de amônia liberada no rúmen, apresentam tendência de variação maior em curto período de tempo se comparados aos teores de albumina sérica. Coincidentemente, o menor teor de NUS $(28,06 \mathrm{mg} / \mathrm{dL})$ foi observado ao mesmo tempo em que o valor de proteína bruta da simulação de pastejo foi menor (Tabela 2). Os teores de NUS acima de $34 \mathrm{mg} / \mathrm{dL}$ ocorreram quando a proteína bruta da simulação de pastejo foi maior que $17 \%$.

A diminuição dos teores dos metabólitos na avaliação do dia 28/12/2005 teve clara associação com a quantidade e qualidade da pastagem natural neste período (Tabela 2). $\mathrm{Na}$ avaliação da pastagem do dia 4/1/2006, houve diminuição da taxa de acúmulo diário $(2,87 \mathrm{~kg} / \mathrm{MS} / \mathrm{dia})$, além de menor proteína bruta na simulação de pastejo $(12,60 \%)$ e aumento da FDN $(75,57 \%)$.

A baixa taxa de parição (70\%) é difícil de ser determinada, uma vez que $95 \%$ das ovelhas foram cobertas durante a estação de monta e o diagnóstico de gestação foi realizado pela observação da taxa de retorno ao cio e, posteriormente, pelo número de ovelhas paridas. Essas perdas podem ter ocorrido por morte embrionária ou, até mesmo, predadores logo após o parto.

Segundo Ferreira (1993), a carência alimentar pode afetar a reprodução pela redução de hormônio folículo estimulante (FSH) e estrógeno proporcionando, entre outras coisas, estros discretos e ausentes e o preparo inadequado do útero nas primeiras fases do desenvolvimento embrionário. Esta carência também pode reduzir a secreção do hormônio luteinizante, diminuindo o nível

Tabela 5 - Relação entre nitrogênio ureico sérico(NUS) no período de monta e taxa de parição das ovelhas sob suplementação com sal orgânico ou sal comum

\begin{tabular}{|c|c|c|c|}
\hline \multirow[t]{2}{*}{ Teor de NUS } & \multicolumn{2}{|c|}{ Tratamento } & \multirow[t]{2}{*}{ Média } \\
\hline & Sal comum & Sal orgânico & \\
\hline \multicolumn{4}{|c|}{ Taxa de parição, \% } \\
\hline$>35 \mathrm{mg} / \mathrm{dL}$ & 58,06 & 69,70 & 60,03 \\
\hline$<35 \mathrm{mg} / \mathrm{dL}$ & 69,39 & 70,21 & 69,80 \\
\hline Média & 65,00 & 70,00 & \\
\hline
\end{tabular}

de progesterona produzida pelo corpo lúteo, comprometendo a gestação.

Não houve diferença $(\mathrm{P}>0,05)$ na taxa de parição entre asovelhas com nível de nitrogênio ureico sérico maior ou menor que $35 \mathrm{mg} / \mathrm{dL}$ (Tabela 5 ). O valor de $35 \mathrm{mg} / \mathrm{dL}$ como interseção para a taxa de parição foi utilizado porque o teor médio para esta variável foi próximo a $35 \mathrm{mg} / \mathrm{dL}$. Isto demonstra que o teor de nitrogênio ureico séricoem ovinos criados extensivamente em pastagem natural, sem suplementação proteica na dieta, não influenciou no desempenho reprodutivo dos animais no presente experimento. Ribeiro et al. (2004) obtiveram resultados semelhantes em pesquisa com ovelhas mestiças Border Leicester $\times$ Texel na qual o teor de nitrogênio ureico sérico não diferiu $(\mathrm{P}>0,05)$ entre ovelhas vazias e gestantes $(7,08$ e 7,61 $\mathrm{mmol} / \mathrm{L}$, respectiva-mente). Esses autores também não encontraram diferenças $(\mathrm{P}>0,05)$ nos teores séricos de albumina, glicose e colesterol entre ovelhas vazias e gestantes e sugeriram que o teor dos metabólitos sanguíneos não varia com o estado reprodutivo em ovelhas bem alimentadas.

Em categorias ovinas com maiores exigências, como ovelhas em lactação, podem ocorrer diferenças mais acentuadas. Foi o que verificaram Brito et al. (2006) em ovelhas Lacaune, em que o teor de nitrogênio ureico séricode ovelhas vazias foi superior $(\mathrm{P}<0,05)$ ao de ovelhas com 60 dias de lactação $(5,46$ e $3,49 \mathrm{mmol} / \mathrm{L}$, respectivamente). Diferenças semelhantes foram verificadas em bovinos leiteiros de alta produção. Ferguson et al. (1993) observaram em vacas que a porcentagem de gestação diminuía em níveis de nitrogênio ureico séricosuperiores a $20 \mathrm{mg} / \mathrm{dL}$. Do mesmo modo, Butler (1998) verificou teor de nitrogênio ureico séricosuperior a $19 \mathrm{mg} / \mathrm{dL}$ associado a redução da concentração plasmática de progesterona e alteração do $\mathrm{pH}$ do ambiente uterino e relacionou esses fatores como principais causas de redução da fertilidade em vacas leiteiras no início da lactação. É possível que estas mesmas explicações sejam aplicáveis a ovelhas especializadas em produção de leite, mas somente para estas.

Não foram verificadas diferenças $(\mathrm{P}>0,05)$ na taxa de parição das ovelhas sob suplementação com sal mineral comum ou orgânico, o que indica que a suplementação mineral orgânica não foi suficiente para melhorar os índices reprodutivos do rebanho. A diferença numérica em favor da suplementação com sal comum não proporcionou ao produtor maior número de cordeiros que justifique esta suplementação.

Além do teor de nitrogênio ureico sérico não ter interferido no desempenho reprodutivo das ovelhas (Tabela 5), os teores médios dos demais componentes metabólicos do sangue, tanto proteico como energéticos, 
não diferiram $(\mathrm{P}>0,05)$ durante a estação de monta entre ovelhas prenhes e vazias.

O fato de a média desses metabólitos ter ficado dentro do intervalo de referência para a espécie citados por Contreras et al. (2000), além da boa disponibilidade forrageira, possivelmente contribuiu para que estes teores não fossem relevantes no desempenho reprodutivo. Em animais de alta produção, é comum que os teores elevados de nitrogênio ureicos sérico prejudiquem o desempenho reprodutivo (Ferguson et al., 1993; Butler et al., 1996), mas, segundo Santos (2000), em animais de média e baixa produção, a ocorrência de baixa ingestão proteica é mais usual, portanto a incidência de altos teores dos metabólitos proteicos no sangue é mais difícil.

Com relação aos níveis de colesterol (Tabela 6), Godoy et al. (2004) descreveram que baixa concentração deste metabólito no ovário pode prejudicar a produção de hormônios esteroides, entretanto neste trabalho esta diferença não ficou evidente $(\mathrm{P}>0,05) \mathrm{e}$, inclusive, o teor de colesterol foi numericamente superior nas ovelhas vazias. Isso pode ter ocorrido pela gestação, que exigiu formação de hormônios esteroides, reabsorvendo parte do colesterol da circulação sanguínea.

Tabela 6 - Médias ajustadas e erros-padrão para albumina, nitrogênio ureico, glicose, colesterol e triglicerídeo séricos, de acordo com o estado reprodutivo das ovelhas

\begin{tabular}{lrrr}
\hline Variável & \multicolumn{2}{c}{ Estado reprodutivo } & \multicolumn{1}{c}{ CV } \\
\cline { 2 - 3 } & \multicolumn{1}{c}{ Prenhes } & \multicolumn{1}{c}{ Vazias } \\
\hline Albumina & $2,83 \pm 0,05$ & $2,81 \pm 0,07$ & 17,63 \\
Ureia & $36,68 \pm 0,67$ & $37,19 \pm 0,98$ & 0,7730 \\
Glicose & $61,42 \pm 1,80$ & $64,89 \pm 2,55$ & 0,6685 \\
Colesterol & $73,95 \pm 2,41$ & $79,98 \pm 3,42$ & 25,40 \\
Triglicerídeo & $22,35 \pm 1,25$ & $24,48 \pm 1,78$ & 28,14 \\
\hline
\end{tabular}

\section{Conclusões}

A suplementação com mineral orgânico durante a estação de monta não melhora a condição reprodutiva de ovelhas, portanto é desnecessária nesse período. Durante a estação de monta, os teores séricos de albumina, ureia, glicose e colesterol variam, mas não alteram o desempenho reprodutivo de fêmeas ovinas.

\section{Referências}

ASSOCIATION OF AMERICAN FEED CONTROL OFFICIAL AAFCO. Official publication. Atlanta, 1997. 266p.

BRITO, M.A.; GONZÁLEZ, F.H.D.; RIBEIRO, L.A.O. et al. Composição do sangue e do leite em ovinos leiteiros no sul do Brasil: variações na gestação e lactação. Ciência Rural, v.36, n.3, p.942-948, 2006.

BUTLER, W.R.; CALAMAN, J.J.; BEAM, S.W. Plasma and milk urea nitrogen in relation to pregnancy rate in lactating dairy cattle. Journal of Animal Science, v.74, p.858-865, 1996.

BUTLER, W.R. Effect of protein nutrition on ovarian and uterine physiology in dairy cattle. Journal of Dairy Science, v.81, n.9, p.2533-2539, 1998.

CONTRERAS, P.; MÖLlER, I.; WITTWER, F. et al. Concentraciones sanguíneas de glucosa, colesterol, cuerpos cetónicos y actividad de aspartato aminotransferasa en ovejas con gestación única y gemelar en pastoreo rotacional intensivo. Archivos de Medicina Veterinaria, v.22, p.65-69, 1990

CONTRERAS, P.A.; WITTWER, F.; BÖHMWALD, H. Uso dos perfis metabólicos no monitoramento nutricional dos ovinos. In: GONZÁLEZ, F.H.D.; DÜRR, J.W.; FONTANELI, R.S.
(Eds.) Perfil metabólico em ruminantes: seu uso em nutrição e doenças nutricionais. Porto Alegre: Gráfica UFRGS, 2000. p. 75-88.

FERGUSON, J.D.; GALLIGAN, D.T.; BLANCHARD, T. et al. Serum urea nitrogen and conception rate: the usefulness of test information. Journal of Dairy Science, v.76, p.3742-3746, 1993.

FERREIRA, A.M. Nutrição e atividade ovariana em bovinos: uma revisão. Pesquisa Agropecuária Brasileira, v.29, n.9, p.1077-1093, 1993.

GODOY, M.M.; ALVES, J.B.; MONTEIRO, A.L.G. et al. Parâmetros reprodutivo e metabólico de vacas da raça Guzerá suplementadas no pré e pós-parto. Revista da Sociedade Brasileira de Zootecnia, v.33, n.1, p.103-111, 2004.

GONZÁLEZ, F.H.D. Indicadores sanguíneos do metabolismo mineral em ruminantes. In: GONZÁLEZ, F.H.D.; DÜRR, J.W.; FOntaneli, R.S. (Eds.) Perfil metabólico em ruminantes: Seu uso em nutrição e doenças nutricionais. Porto Alegre: Gráfica UFRGS, 2000a. p.31-52.

GONZÁLEZ, F.H.D. Uso do perfil metabólico para determinar o status nutricional em gado de corte. In: GONZÁLEZ, F.H.D.; DÜRR, J.W.; FOnTANeli, R.S. (Eds.) Perfil metabólico em ruminantes: Seu uso em nutrição e doenças nutricionais. Porto Alegre: Gráfica UFRGS, 2000b. p.63-74.

HERINGER, I.; JACQUES, A.V.A. Acumulação de forragem e material morto em pastagem nativa sob distintas alternativas de manejo em relação às queimadas. Revista Brasileira de Zootecnia, v.31, n.2, p.599-604, 2002.

OSPINA, H.P. Efeito de quatro níveis de "carboquelatos" em sais mineralizados sobre o consumo e digestibilidade de feno de baixa qualidade em bezerros. In: REUNIÃO ANUAL DA SOCIEDADE BRASILEIRA DE ZOOTECNIA, 37., 2000, Viçosa, MG. Anais... Viçosa, MG: Sociedade Brasileira de Zootecnia, 2000. (CD-ROM).

PAYNE, J.M., PAYNE, S. The metabolic profile test. Oxford: Oxford University Press. 1987. 179p. 
RIBEIRO, L.A.O.; GONZÁLEZ, F.H.D.; CONCEIÇÃO, T.R. et al. Perfil metabólico de borregas Corriedale em pastagens nativas do Rio Grande do Sul. Acta Scientiae Veterinariae, v.31, n.3, p.167-170, 2003 .

RIBEIRO, L.A.O.; MATTOS, R.C.; GONZÁLEZ, F.H.D. et al. Perfil metabólico de ovelhas Border Leicester x Texel durante a gestacão e a lactação. Revista Portuguesa de Ciências Veterinárias, v.99, p.155-159, 2004.

ROWLANDS, G.J. A review of variations in the concentrations of metabolites in the blood of beef and dairy cattle associated with physiology, nutrition and disease, with particular reference to the interpretation of results. World Review of Nutrition and Dietics, v.35, p.172-235, 1980 .
SANTOS, J.E.P. Importância da alimentação na reprodução da fêmea bovina. In: WORKSHOP SOBRE REPRODUÇÃO ANIMAL, 1., 2000, Pelotas. Anais... Pelotas: EMBRAPA, 2000. p.7-82.

STATISTICAL ANALYSIS SYSTEM - SAS. SAS/STAT user's guide: statistics. 7.ed. Version 6.11. Cary: SAS Institute, 1997. v.2. 493p.

SILVA, C.A.M. Reproductive wastage in sheep. Santa Maria: Universidade Federal de Santa Maria - FAO - UNO, 1992. 45p

WILM, H.G.; COSTELLO, D.F.; KLIPPLE, G.E. Estimating forage yield by the double-sampling methods. Agronomy Journal, v.36, p.194-203, 1944.

WITTWER, F.; REYES, J.M.; OPITZ, H. et al. Determinación de urea en muestras de leche de rebaños bovinos para el diagnóstico de desbalance nutricional. Archivo Medico Veterinario, v.25, p.165-172, 1993. 